\title{
Statins and therapy of Alzheimer's disease: questions of efficacy versus trial design
}

Benjamin Wolozin*1,2

\begin{abstract}
Recent trials of statins produced no benefit for subjects with Alzheimer's disease. These negative studies add to a growing list of negative clinical trials. These data point to a need for reevaluating the pathophysiology of late-onset Alzheimer's disease. Late-onset Alzheimer's disease might result from the cumulative effects of at least four different factors: $\beta$-amyloid accumulation, cardiovascular disease, aging and the associated loss of synaptic plasticity, and inflammation. Successful therapy of subjects with overt dementia might require approaches targeting all four pathophysiological domains.
\end{abstract}

Since we first reported the reduced incidence of Alzheimer's disease (AD) among subjects using statins, many other epidemiological studies have repeated this finding [1-11], and only one study has failed to observe this effect [3]. However, epidemiology is meant to generate hypotheses but does not prove efficacy. The critical test comes with prospective clinical trials. The first major prospective clinical trial of a statin, the Lipitor's Effect in Alzheimer Dementia (LEADe) study of atorvastatin, gave the first sign that the data suggested from epidemiological studies do not translate to prospective clinical trials [12]. Next, a trial run by Sano and colleagues [13] presented further results, this time with simvastatin, for lack of protection against the progression of cognitive decline among subjects with AD. The results from the study by Sano and colleagues show a strikingly null effect; the placebo and treatment groups are practically identical. As Sano stated after her initial presentation at the 2009 International Conference on Alzheimer's disease, 'At least we have shown that there is

\footnotetext{
*Correspondence: bwolozin@bu.edu

'Departments of Pharmacology and Neurology, Boston University School of Medicine, 715 Albany Street, Room R614, Boston, MA 02118-2526, USA

Full list of author information is available at the end of the article
}

no deleterious effect associated with use of simvastatin' (M Sano, personal communication, 12 July 2009).

This negative trial adds to an increasing string of negative clinical trials observed for treatments whose efficacy was hypothesized on the basis of either animal studies or epidemiological studies (reviewed by Kivipelto and colleagues [14]). This group includes $\gamma$-secretase inhibitors (semagacestat), $\gamma$-secretase modulators ( $r$-flurbiprofen), vaccines (AN1792), non-steroidal anti-inflammatory drugs, anti-oxidants (vitamin E), a mitochondrial directed agent (Dimebon; Pfizer Inc, New York, NY, USA), anti-aggregation agents (Alzhemed; Neurochem Inc., now part of Bellus Health Inc., Laval, QC, Canada), and many other medications. In the case of the simvastatin trial, biomarker data suggest that simvastatin achieves the desired cholesterol-reducing actions. The trial did not measure 24-hydroxycholesterol, which is a biomarker for cholesterol turnover in the brain, but multiple studies have demonstrated that simvastatin does lower 24-hydroxycholesterol in humans and in animal models [15].

Part of the answer explaining the negative results might lie in an incomplete conceptualization of the pathophysiology of $\mathrm{AD}$. The simplest model for $\mathrm{AD}$ assumes that the disease results primarily from the accumulation of $\beta$-amyloid $(A \beta)$ and the resulting toxicity. This hypothesis applies best to familial AD cases, which result from mutations in proteins directly linked to the $A \beta$ metabolism (amyloid precursor protein and presenilins), and the disease commonly presents in patients who are much younger than those with classic late-onset AD.

Discussions of late-onset AD typically divide the disease course into at least three phases: prodromal, mild cognitive impairment, and overt dementia. To understand how these stages might impact on therapy, we need to think mechanistically. Integrating the breadth of research in $A D$ suggests that late-onset $A D$ might actually result from multiple factors rather than simply from the accumulation of $A \beta$. These include at least four general factors:

1. $A \beta$ : The accumulation of $A \beta$ is clearly relevant to lateonset $\mathrm{AD}$ because of the strong presence of amyloid and tau pathology in late-onset $\mathrm{AD}$ combined with the 
strong data implicating amyloid precursor protein and presenilins in the pathophysiology of familial AD. However, $A \beta$ does not appear to be acutely toxic in vivo. Many subjects exhibit $A \beta$ accumulation without experiencing dementia, and this raises the possibility that $A \beta$ levels might exert an influence that is only partly causative. Genetic considerations emphasize the issue of incomplete causation. Genetic data for genes linked to late-onset $\mathrm{AD}$, aside from apolipoprotein $\mathrm{E}$ (ApoE), all exhibit modest effects.

2. Cardiovascular disease: Mid-life cardiovascular risk factors, such as high cholesterol, high blood pressure, diabetes, and obesity, all are associated with increased risk of late-onset AD. Patients with AD consistently exhibit reduced levels of cerebral blood flow, which no doubt lead to reduced cognitive reserve. Reduced cerebral blood flow could result from vascular disease associated with cardiovascular disease and diabetes and aggravated by deposition of $\mathrm{A} \beta$ around the cerebral microvasculature. In a sense, this reduction of cerebral blood flow can be reclassified as end-organ disease of the brain for subjects with cardiovascular disease. The epidemiological data suggesting a protective benefit of statin use might easily reflect moderation of cardiovascular disease and increasing cerebral blood flow.

3. Aging, plasticity, and regeneration: Aging leads to reduced plasticity and impaired proteostasis. ApoE4 is the major risk factor for late-onset AD. Much attention has been focused on the tendency of ApoE to promote $A \beta$ aggregation and accumulation; however, ApoE4 is equally notable because it leads to reduced plasticity and regeneration.

4. Inflammation: Neurodegeneration and aging both stimulate strong inflammatory responses.

Frank dementia occurs late in the disease course at a point when all four factors are impacting on the brain and have impacted on the brain for years. Statins are outstanding medications that can prevent further cardiovascular damage and even improve cardiovascular function but are not regenerative medicines. Statins are unable to restore the function of an end-organ tissue back to the function before cardiovascular disease was present. By analogy, if dementia results from long-term cardiovascular disease, then statins might be unable to benefit subjects once overt dementia is apparent. The window of opportunity for statins might require that treatment begin at mid-life, when statins can function as a protective factor rather than as a treatment that actively reduces dementia once it has occurred. The same set of considerations might apply to anti-amyloid strategies because $A \beta$ accumulation also occurs over a long time frame.

Most clinical trial designs focus on subjects who already have dementia, which represents a late stage in disease if we consider dementia to be analogous to endorgan disease. If dementia results from the interaction of these four factors, then treatment strategies might need to target each factor to be effective. Treatments will need to prevent further damage by inhibiting cardiovascular disease and increasing cerebral blood flow. In this context, medicines such as angiotensin receptor blockers might be useful because they appear to particularly benefit those suffering from dementia [16].

At the same time, treatments will need to reduce the ongoing toxicity resulting from the presence of protein aggregates, including $A \beta$, tau, and other proteins. Increasing data suggest that multiple pathological proteins in addition to $A \beta$ are secreted in $A D$; these proteins include oligomeric forms of tau and perhaps $\alpha$-synuclein. Thus, although anti-amyloid antibody therapy has yet to show promise, concurrent administration of antibodies against oligomeric $A \beta$ and tau might be effective. The associated inflammation will need to be dampened. Nonsteroidal anti-inflammatory drugs could be helpful, but novel anti-inflammatory drugs, termed resolvins, might prove even more effective [17]. Finally, the underlying deficits in regeneration, resulting from aging and ApoE4, will need to be addressed. Whether SirT1 agonists, such as resveratrol or its analogues, will prove effective in the brain remains to be determined. The only therapeutic targets that might actually lead to a dramatic improvement in subjects with dementia are those targeting regeneration and plasticity, because only those therapies would elicit an actively beneficial response in older patients.

\section{Abbreviations}

$A \beta, \beta$-amyloid; AD, Alzheimer's disease; ApoE, apolipoprotein $E$.

\section{Competing interests}

BW holds a patent for use of statins in therapy of Alzheimer's disease.

\section{Acknowledgments}

This work was supported by awards to BW (National Institutes of Health grants NINDS NS066108, NS073679, NIEHS ES15567, and NINDS NS060872).

\section{Author details}

'Departments of Pharmacology and Neurology, Boston University School of Medicine, 715 Albany Street, Room R614, Boston, MA 02118-2526, USA. ${ }^{2}$ Geriatric Research, Education and Clinical Center, Edith Nourse Rogers Memorial Veterans Affairs Center, 200 Springs Road, Bedford, MA 01730, USA.

Published: 16 January 2012

\section{References}

1. Wolozin B, Kellman W, Ruosseau P, Celesia GG, Siegel G: Decreased prevalence of Alzheimer disease associated with 3-hydroxy-3methyglutaryl coenzyme A reductase inhibitors. Arch Neurol 2000 57:1439-1443.

2. Wolozin B, Manger J, Bryant R, Cordy J, Green RC, McKee A: Re-assessing the relationship between cholesterol, statins and Alzheimer's disease. Acta Neurol Scand Suppl 2006, 185:63-70.

3. Zandi PP, Sparks DL, Khachaturian AS, Tschanz J, Norton M, Steinberg M, Welsh-Bohmer KA, Breitner JC; Cache County Study investigators: Do statins reduce risk of incident dementia and AD? The Cache County Study. Arch Gen Psychiatry 2004, 62:217-224. 
4. Sjogren M, Mielke M, Gustafson D, Zandi P, Skoog I: Cholesterol and Alzheimer's disease - is there a relation? Mech Ageing Dev 2006, 127:138-147.

5. Rea TD, Breitner JC, Psaty BM, Fitzpatrick AL, Lopez OL, Newman AB, Hazzard WR, Zandi PP, Burke GL, Lyketsos CG, Bernick C, Kuller LH: Statin use and the risk of incident dementia: the Cardiovascular Health Study. Arch Neurol 2005, 62:1047-1051.

6. Green RC, MCNagny SE, Jayakumar P, Cupples LA, Benke K, Farrer LA: Statin use and the risk of Alzheimer's disease. Alzheimer's \& Dementia 2006 , 2:96-1003.

7. Li G, Higdon R, Kukull WA, Peskind E, Van Valen Moore K, Tsuang D, van Belle G, McCormickW, Bowen JD, Teri L, Schellenberg GD, Larson EB: Statin therapy and risk of dementia in the elderly: a community-based prospective cohort study. Neurology 2004, 63:1624-1628.

8. Li G, Larson EB, Sonnen JA, Shofer JB, Petrie EC, Schantz A, Peskind ER, Raskind MA, Breitner JC, Montine TJ: Statin therapy is associated with reduced neuropathologic changes of Alzheimer disease. Neurology 2007, 69:878-885.

9. Masse I, Bordet R, Deplanque D, Al Khedr A, Richard F, Libersa C, Pasquier F: Lipid lowering agents are associated with a slower cognitive decline in Alzheimer's disease. J Neurol Neurosurg Psychiatry 2005, 76:1624-1629.

10. Rockwood K, Kirkland S, Hogan DB, MacKnight C, Merry H, Verreault R, Wolfson C, McDowell I: Use of lipid-lowering agents, indication bias, and the risk of dementia in community-dwelling elderly people. Arch Neurol 2002, 59:223-227.

11. Zhou B, Teramukai S, Fukushima M: Prevention and treatment of dementia or Alzheimer's disease by statins: a meta-analysis. Dement Geriatr Cogn Disord 2007, 23:194-201.

12. Feldman HH, Doody RS, Kivipelto M, Sparks DL, Waters DD, Jones RW, Schwam E, Schindler R, Hey-Hadavi J, DeMicco DA, Breazna A: Randomized controlled trial of atorvastatin in mild to moderate Alzheimer disease: LEADe. Neurology 2010, 74:956-964.

13. Sano M, Bell KL, Galasko D, Galvin JE, Thomas RG, van Dyck CH, Aisen PS: A randomized, double-blind, placebo-controlled trial of simvastatin to treat Alzheimer disease. Neurology 2010, 77:556-563.

14. Mangialasche F, Solomon A, Winblad B, Mecocci P, Kivipelto M: Alzheimer's disease: clinical trials and drug development. Lancet Neurol 2010, 9:702-716.

15. Vega GL, Weiner MF, Lipton AM, Von Bergmann K, Lutjohann D, Moore C, Svetlik D: Reduction in levels of 24S-hydroxycholesterol by statin treatment in patients with Alzheimer disease. Arch Neurol 2003, 60:510-515.

16. Li NC, Lee A, Whitmer RA, Kivipelto M, Lawler E, Kazis LE, Wolozin B: Use of angiotensin receptor blockers and risk of dementia in a predominantly male population: prospective cohort analysis. BMJ 2010, 340:b5465.

17. Van Dyke TE: Proresolving lipid mediators: potential for prevention and treatment of periodontitis. J Clin Periodontol 2011, 38 Suppl 11:119-125.

doi:10.1186/alzrt101

Cite this article as: Wolozin B: Statins and therapy of Alzheimer's disease: questions of efficacy versus trial design. Alzheimer's Research \& Therapy 2012, 4:3. 